\title{
Mechanics of masonry in compression: Results from a homogenisation approach
}

\author{
A. Zucchini ${ }^{a, *}$, P.B. Lourenço ${ }^{\text {b, } 1}$ \\ a ENEA, FIS.MET, C.R.E. “E.Clementel”, v. Don Fiammelli, 2, I-40129 Bologna, Italy \\ ${ }^{\mathrm{b}}$ University of Minho, Department of Civil Engineering, Azurém, $P-4800-058$ Guimarães, Portugal
}

Received 2 November 2005; accepted 8 August 2006

Available online 1 November 2006

\begin{abstract}
Despite considerable experimental and analytical research in the past, modern regulations still adopt very conservative simplified formulas for the compressive strength of masonry. The present paper contributes to the understanding of masonry under compression, using a novel non-linear homogenisation tool that includes the possibility of tensile and compressive progressive damage, both in the unit and mortar. The simplified homogenised model uses an iterative procedure and a few ingenious micro-deformation mechanisms, being able to accurately reproduce complex simulations carried out with non-linear continuum finite element analysis, at a marginal cost of CPU time and with no convergence difficulties. In addition, the comparison of the model with experimental results available in the literature indicates that an estimation of the compressive strength of masonry better than the one provided by the codes is possible, using the mechanical and geometrical properties of the masonry components.
\end{abstract}

(C) 2006 Elsevier Ltd. All rights reserved.

Keywords: Masonry; Compression; Micro-modelling; Homogenisation; Compressive strength

\section{Introduction}

The mechanical behaviour of different unreinforced masonry types is generally characterised by the same common feature: a very low tensile strength. This property is so important that it has determined the shape of ancient constructions until the 19th century. For more than ten thousand years, masonry structures have been used only in compression, and this is still a normal practice nowadays unless reinforced or prestressed masonry is used. Therefore, the compressive strength of masonry in the direction normal to the bed joints has been traditionally regarded as the sole relevant structural material property, at least

\footnotetext{
* Corresponding author. Tel.: +39 0516098256; fax: +39 0516098062.

E-mail addresses: zucchini@bologna.enea.it (A. Zucchini),pbl@civil. uminho.pt (P.B. Lourenço).

${ }^{1}$ Tel.: +351 253 510200; fax: +351 253510217 .
}

until the recent introduction of numerical methods for masonry structures.

The conventional uniaxial compressive strength of masonry in the direction normal to the bed joints can be obtained from the European standards CEN [1], shown in Fig. 1(a). The CEN specimen is however large and costly to execute, requiring very large loads at failure, especially when compared to the standard cube or cylinder tests for concrete. A simpler test frequently used to obtain the vertical uniaxial compressive strength is the stacked bond prism, see Fig. 1(b), even if it is clear that this test provides slightly different results than the standard test [2-4].

The study of stacked masonry under compression made possible the development of simple compression failure theories, see [5] for details. Since the pioneering work of Hilsdorf [6] it has been generally accepted that the difference in elastic properties of the unit and mortar is the precursor of failure. Uniaxial compression of masonry leads to a state of tri-axial compression in the mortar and of 


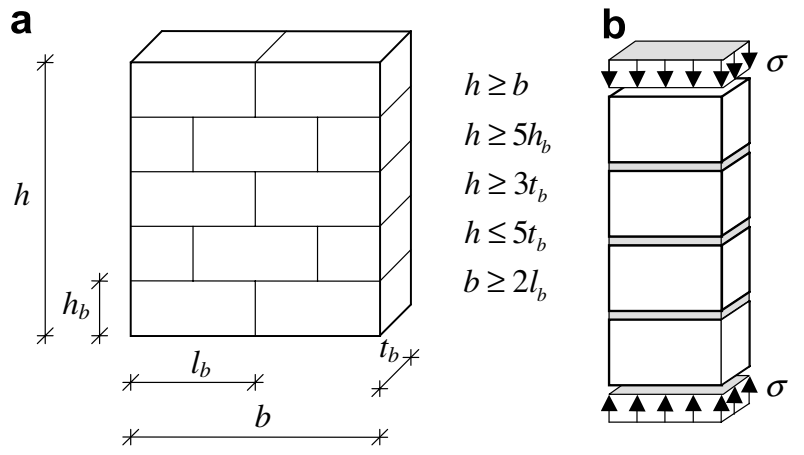

Fig. 1. Aspects related to masonry compression: (a) schematic representation of CEN test specimen, CEN (1999); (b) stacked bond prism.

compression/biaxial tension in the unit. This issue was further pursued by several authors, particularly by McNary and Abrams [7] that report a comprehensive testing program aiming at the tri-axial characterisation of brick and mortar. Recently, sophisticated non-linear analyses of masonry under compression have been carried out using continuum finite element models. The problem of reproducing the experimental response of the masonry composite from the behaviour of masonry components is rather difficult due to the number of influencing parameters and the complex micro-structure, but some authors seem to have succeeded, e.g. Brencich et al. [8]. The validity of simplified approaches assuming uniform states of stress in masonry components and more complex approaches using continuum finite elements have been questioned by Shrive and Jessop [9] and Pina-Henriques and Lourenço [10].

The need for further research is confirmed by the fact the modern codes, CEN [11] and ACI [12], refuse to accept any simplified theory. The compressive strength of masonry can only be determined using empirical formulas (of course conservative because they result from a lower envelope of a failure database) or experimental testing for the specific combination of geometry and materials. The present paper aims at further discussing the mechanics of masonry under compression and at proposing a homogenisation tool that is able to reproduce the results of advanced non-linear finite element computations, at a marginal fraction of the cost. For this purpose, a homogenisation approach previously developed by the authors $[13,14]$ is extended for the first time to the case of masonry under compression. With this extension and after validation of the theory, a thorough discussion on the most significant parameters affecting the behaviour of masonry under compression is made and the homogenisation approach is used for a comparison with experimental results available in the literature. It is believed that the paper represents a significant contribution to the discussion of masonry behaviour under compression, much more than a simple extension of a homogenisation model that proved to yield adequate results in terms of elastic results and tensile loading. It is much relevant that the proposed simplified approach provides results almost equal to very complex non-linear finite element analysis of a masonry representative volume.

\section{Formulation of the model}

\subsection{General}

Zucchini and Lourenço [13] have shown that the elastic mechanical properties of an orthotropic material equivalent to a basic masonry cell can be derived from a suitable micromechanical model with appropriate deformation mechanisms, which take into account the staggered alignment of the units in a masonry wall. The unknown internal stresses and strains can be found from equilibrium equations at the interfaces between the basic cell components, from a few ingenuous assumptions on the kinematics of the basic cell deformation and by forcing the macro-deformations of the model and of the homogeneous material to contain the same strain energy. This homogenisation model has already been extended with good results to non-linear problems in the case of a masonry cell failure under tensile loading parallel to the bed joint [14]. The simulation has been accomplished by coupling the elastic micromechanical model with a damage model for joints and units by means of an iterative solution procedure to calculate the damage coefficients. A simple isotropic damage model with only one single parameter has been utilized, because the discrete internal structure of the cell, and implicitly its global anisotropic behaviour, is taken into account by the three-dimensional micromechanical model. The geometry for the basic masonry cell and its components is shown in Fig. 2, where it can be seen that the complex geometry is replaced by four components, namely unit, bed joint, head joint and cross joint.

\subsection{Adopted coupled homogenisation-damage model}

This paper addresses the problem of a basic masonry cell under compressive loading perpendicular to the bed joint. When the basic cell is loaded only with normal stresses, the micromechanical model of Zucchini and Lourenço [13] assumes that all shear stresses and strains inside the basic cell can be neglected, except the in-plane shear stress and strain $\left(\sigma_{x y}\right.$ and $\left.\varepsilon_{x y}\right)$ in the bed joint and in the unit. The non-zero stresses and strains in the bed joint, head joint and unit are assumed to be constant, with the exception of the normal stress $\sigma_{x x}$ in the unit, which is a linear function of $x$ and accounts for the effect of the shear $\sigma_{x y}$ in the bed joint, and with the exception of the shear stress $\sigma_{x y}$ in the unit, which is linear in $y$.

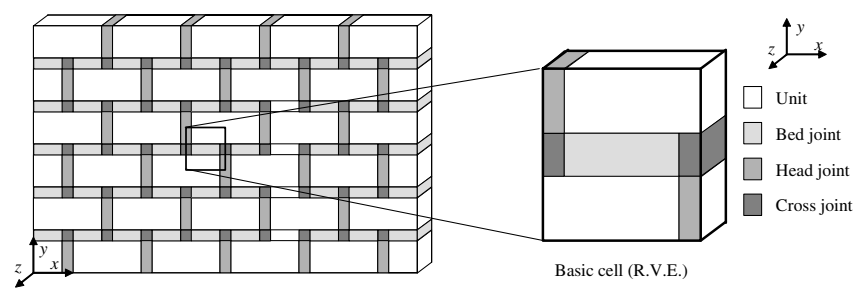

Fig. 2. Basic cell for masonry and homogenisation process. 
The coupling of this model with a material damage model in tension [14] leads to an iterative algorithm, in which at each cycle a system of equilibrium equations is solved to obtain the unknown effective stresses and strains, making use of the damage coefficients from the previous iteration. The damage coefficients can then be updated, by means of the damage model, from the new stresses and the process is iterated until convergence of the coefficients, within an input tolerance. Finally, the damaged internal stresses in the cell components and the unknown homogenised stresses and strains can be derived from the values of the converged internal stresses.

The governing linear system of 20 equilibrium equations in the unknown internal stresses and strains of the masonry cell, to be solved at each iteration, can be rewritten for a strain driven compression in $y$, as

$r^{2} \sigma_{x x}^{2}=r^{b} \bar{\sigma}_{x x}^{b}-\frac{l-t}{2 h} r^{1} \sigma_{x y}^{1} \quad$ Interface brick-head joint

$r^{b} \sigma_{y y}^{b}=r^{1} \sigma_{y y}^{1} \quad$ Interface brick-bed joint

$h r^{2} \sigma_{x x}^{2}+2 t r^{1} \sigma_{x x}^{1}+h r^{b} \bar{\sigma}_{x x}^{b}+(l-t) r^{1} \sigma_{x y}^{1}=0 \quad$ Right boundary

$\left(h+4 t \frac{r^{2}}{r^{1}+r^{2}}\right) \varepsilon_{y y}^{2}+h \varepsilon_{y y}^{b}=2(h+t) \varepsilon_{y y}^{0} \quad$ Upper boundary

$t h r^{2} \sigma_{z z}^{2}+\left(l-t+t \frac{r^{1}+r^{2}}{r^{1}}\right) t r^{1} \sigma_{z z}^{1}+l h r^{b} \sigma_{z z}^{b}=0$

Front boundary

$2 t \varepsilon_{y y}^{1}+h \varepsilon_{y y}^{b}=\left(4 t \frac{r^{2}}{r^{1}+r^{2}}+h\right) \varepsilon_{y y}^{2} \quad$ Upper boundary

$t \varepsilon_{x x}^{2}+l \bar{\varepsilon}_{x x}^{b}=\left(l-t+4 t \frac{r^{1}}{r^{1}+r^{2}}\right) \varepsilon_{x x}^{1} \quad$ Right boundary

$\varepsilon_{z z}^{b}=\varepsilon_{z z}^{1} \quad$ Front boundary

$\varepsilon_{z z}^{b}=\varepsilon_{z z}^{2} \quad$ Front boundary

$$
\begin{aligned}
\varepsilon_{x x}^{k} & =\frac{1}{E^{k}}\left[\sigma_{x x}^{k}-v^{k}\left(\sigma_{y y}^{k}+\sigma_{z z}^{k}\right)\right] \\
\varepsilon_{y y}^{k} & =\frac{1}{E^{k}}\left[\sigma_{y y}^{k}-v^{k}\left(\sigma_{x x}^{k}+\sigma_{z z}^{k}\right)\right] \quad k=b, 1,2 \\
\varepsilon_{z z}^{k} & =\frac{1}{E^{k}}\left[\sigma_{z z}^{k}-v^{k}\left(\sigma_{x x}^{k}+\sigma_{y y}^{k}\right)\right] \\
\varepsilon_{x y}^{1} & =\frac{\varepsilon_{x x}^{2}-\bar{\varepsilon}_{x x}^{b}}{4}-\left(\frac{l-t}{8 h E^{b}}+\frac{h}{6 t G^{b}}\right) \frac{r^{1}}{r^{b}} \sigma_{x y}^{1} \\
\sigma_{x y}^{1} & =2 G^{1} \varepsilon_{x y}^{1}
\end{aligned}
$$

As shown in Fig. 3, $l$ is half of the unit length, $h$ is half of the unit height and $t$ is half of the bed joint width. Here also, $E$ is the Young modulus, $G$ is the shear modulus, $v$ is the Poisson coefficient, $\varepsilon_{i j}$ is the strain component and $\sigma_{i j}$ is the stress component. Unit, bed joint, head joint and cross joint variables are indicated throughout this paper, respectively, by the superscripts $b, 1,2$ and 3 , according to Fig. 3. $\bar{\sigma}_{x x}^{b}$ and $\bar{\varepsilon}_{x x}^{b}$ are the mean value of the (non-constant) normal stress $\sigma_{x x}$ and of the (non-constant) normal strain $\varepsilon_{x x}$ in the unit, respectively. $\varepsilon_{y y}^{0}$ is the uniform normal (macro) strain, perpendicular to the bed joint, on the faces of the homogenised basic cell. Finally, $r=1-d$, where $d$ is the scalar damage coefficient, ranging from 0 to 1 and representing a measure of the material damage. The damaged $\boldsymbol{\sigma}_{\mathrm{d}}$ and undamaged (or effective) stresses $\boldsymbol{\sigma}$ are correlated by the relation

$\boldsymbol{\sigma}_{\mathrm{d}}=(1-d) \mathbf{D} \boldsymbol{\varepsilon}=(1-d) \boldsymbol{\sigma}$

where $\mathbf{D}$ is the elastic operator.

The adopted damage model in tension [14] is a simple scalar isotropic model, with a Rankine type damage surface:

$\sigma_{\mathrm{p}}=\sigma_{\mathrm{t}}$

where $\sigma_{\mathrm{p}}$ is the maximum effective principal stress and $\sigma_{\mathrm{t}}$ the tensile strength of the given cell component. In the unit, where the normal stress $\sigma_{x x}^{b}$ varies linearly in the $x$ direction, the damage is controlled by the maximum principal

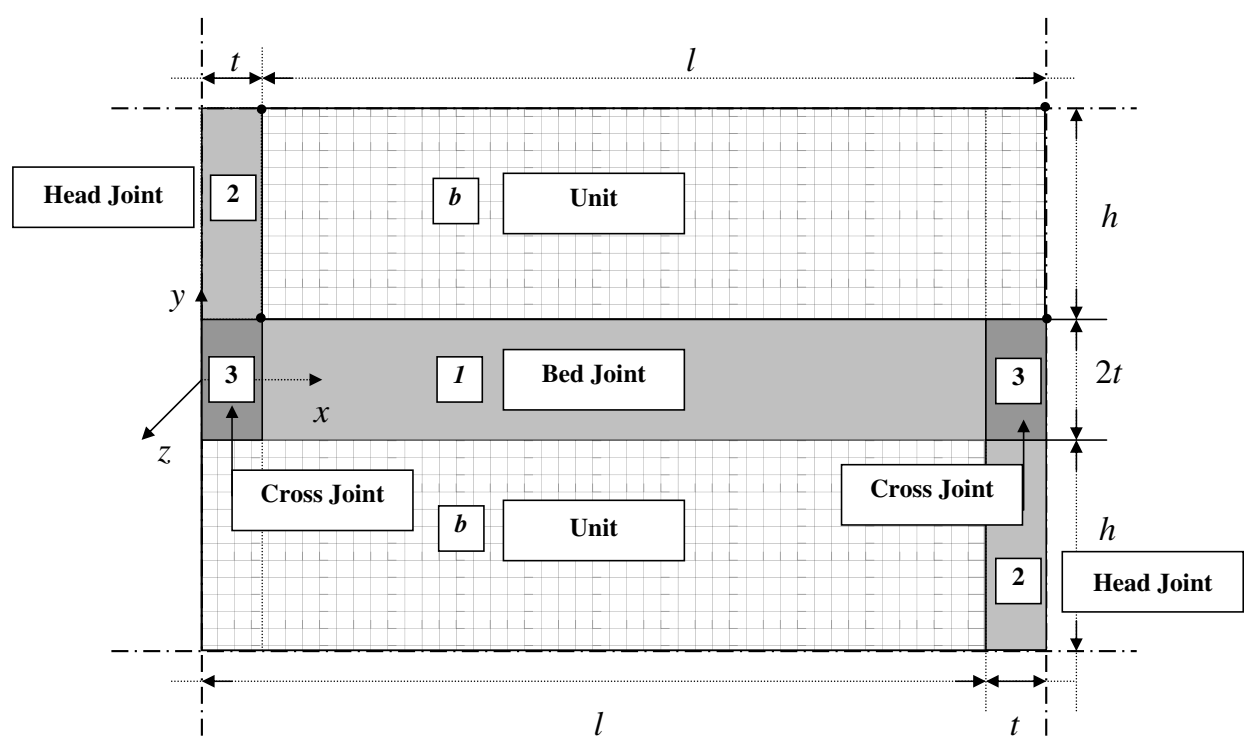

Fig. 3. Definition of masonry axes and masonry components considered in the adopted formulation: unit, head joint, bed joint and cross joint. 
stress in the entire unit and not by the maximum principal stress obtained with the average value $\bar{\sigma}_{x x}^{b}$.

The damage can only increase monotonically with the evolution law

$d=1-\frac{\sigma_{\mathrm{t}}}{\sigma_{\mathrm{p}}} \mathrm{e}^{A\left(1-\frac{\sigma_{\mathrm{p}}}{\sigma_{\mathrm{t}}}\right)} \quad \sigma_{\mathrm{t}} \leqslant \sigma_{\mathrm{p}} \leqslant \infty$

The parameter $A$ is related to the mode I or mode II fracture energies $\left(G^{\mathrm{I}}\right.$ and $\left.G^{\mathrm{II}}\right)$ and strengths $\left(\sigma_{\mathrm{t}}\right.$ and $\left.\sigma_{\mathrm{s}}\right)$ of the material, respectively, by

$A_{\mathrm{t}}=\left(\frac{G^{\mathrm{l}} E}{l \sigma_{\mathrm{t}}^{2}}-\frac{1}{2}\right)^{-1} \quad A_{\mathrm{s}}=\left(\frac{G^{\mathrm{II}} G}{l \sigma_{\mathrm{s}}^{2}}-\frac{1}{2}\right)^{-1}$

where $E$ and $G$ are the Young and shear moduli and $l$ is the characteristic internal length of fracture [15], which is assumed here to be the material dimension in the direction of the load.

\subsection{Extension of the formulation with a plasticity model in compression}

In a basic masonry cell under vertical compressive load, the elastic mismatch between the unit and the bed joint is responsible for a tension-compression state, in the plane perpendicular to the loading, of these two components, with the stiffer one in tension. Failure or degradation of the cell properties, under increasing load, can be caused by either high tension or compression stresses in the component materials. The study of the inelastic behaviour of the basic cell in compression up to failure requires therefore the introduction of a non-linear constitutive model in compression. A Drucker-Prager model has been adopted for the simulation of the plastic deformation of each cell components. Its classic formulation [16] reads as

$3 k_{1} \sigma_{m}+\bar{\sigma}-k_{2}=0$

where

$\sigma_{m}=\frac{\sigma_{i i}}{3}=-p, \quad \bar{\sigma}=\sqrt{\frac{1}{2} \sigma_{i j}^{\prime} \sigma_{i j}^{\prime}}=\frac{q}{\sqrt{3}}$

$k_{1}=\frac{2 \sin \phi_{\mathrm{f}}}{\sqrt{3}\left(3-\sin \phi_{\mathrm{f}}\right)}, \quad k_{2}=\frac{6 \cos \phi_{\mathrm{f}}}{\sqrt{3}\left(3-\sin \phi_{\mathrm{f}}\right)} c$

Introducing the deviatoric stress measure $t=\alpha_{\mathrm{f}} q$ with

$\alpha_{\mathrm{f}}=\frac{3-\sin \phi_{\mathrm{f}}}{6 \cos \phi_{\mathrm{f}}}$

it is possible to obtain

$t-p \tan \phi_{\mathrm{f}}=c$

which defines the friction angle $\phi_{\mathrm{f}}$ and the cohesion $c$ in the meridional plane $\mathbf{t}-\mathbf{p}$.

In uniaxial compression $q=\sigma_{\mathrm{c}}$ and $p=\frac{\sigma_{\mathrm{c}}}{3}$, providing the correlation of cohesion to uniaxial experimental yield stress in compression $\sigma_{\mathrm{c}}$ :

$c=\frac{1-\sin \phi_{\mathrm{f}}}{2 \cos \phi_{\mathrm{f}}} \sigma_{\mathrm{c}}$
The unknown plastic strains $\boldsymbol{\varepsilon}_{\mathrm{p}}$ of the Drucker-Prager model are assumed to be constant in each cell component and can be derived from the total (elastic + plastic) strains $\varepsilon_{\mathrm{t}}$ with the return mapping algorithm, i.e. by integration over the loading path of the following system of incremental elasto-plastic equations from stage $n-1$ to stage $n$, e.g. [17]:

$\left\{\begin{array}{cl}\boldsymbol{\sigma}^{n}=\boldsymbol{\sigma}^{*}-\mathbf{D} \Delta \varepsilon_{\mathrm{p}}^{n} & \text { plastic corrector } \\ \Delta \varepsilon_{\mathrm{p}}^{n}=\Delta \lambda^{n} \frac{\partial g\left(\boldsymbol{\sigma}^{n}, \varepsilon_{\mathrm{p}, \mathrm{eq}}^{n}\right)}{\partial \boldsymbol{\sigma}^{n}} & \text { flow rule } \\ f\left(\boldsymbol{\sigma}^{n}, \varepsilon_{\mathrm{p}, \mathrm{q}}^{n}\right)=t^{n}-p^{n} \tan \phi_{\mathrm{f}}\left(\varepsilon_{\mathrm{p}, \mathrm{eq}}^{n}\right) & \\ -c\left(\varepsilon_{\mathrm{p}, \mathrm{eq}}^{n}\right)=0 & \text { yield surface }\end{array}\right.$

Here the vector notation for stress and strains is used, being $\mathbf{D}$ the elastic stiffness matrix, $\boldsymbol{\sigma}^{*}$ the elastic predictor

$\boldsymbol{\sigma}^{*}=\boldsymbol{\sigma}^{n-1}+\mathbf{D} \Delta \varepsilon_{\mathrm{t}}^{n}$

$g$ the non-associated plastic potential

$g\left(\boldsymbol{\sigma}, \varepsilon_{\mathrm{p}, \mathrm{eq}}\right)=t-p \tan \phi_{\mathrm{d}}-c$

in general with a dilatancy angle $\phi_{\mathrm{d}} \neq \phi_{\mathrm{f}}$, and finally $\varepsilon_{\mathrm{p}, \mathrm{eq}}^{n}$ the equivalent plastic strain

$\Delta \varepsilon_{\mathrm{p}, \mathrm{eq}}^{n}=\sqrt{\frac{2}{3}\left(\Delta \overline{\boldsymbol{\varepsilon}}_{\mathrm{p}}^{n}\right)^{\mathrm{T}}\left(\Delta \bar{\varepsilon}_{\mathrm{p}}^{n}\right)}$

where the notation $\overline{\boldsymbol{\varepsilon}}_{\mathrm{p}}$ means the vector $\overline{\boldsymbol{\varepsilon}}_{\mathrm{p}}^{\mathrm{T}}=\left\{\varepsilon_{\mathrm{p} 1}, \varepsilon_{\mathrm{p} 2}, \varepsilon_{\mathrm{p} 3}\right.$, $\left.\sqrt{2} \varepsilon_{\mathrm{p} 4}, \sqrt{2} \varepsilon_{\mathrm{p} 5}, \sqrt{2} \varepsilon_{\mathrm{p} 6}\right\}$. Now combining Eqs. (23) and (25) results in

$\Delta \boldsymbol{\varepsilon}_{\mathrm{p}}^{n}=\Delta \lambda^{n}\left(\frac{\sqrt{3}}{2 q^{n}} \mathbf{s}^{n}+\frac{\tan \phi_{\mathrm{d}}}{3 \sqrt{3} \alpha_{\mathrm{f}}} \mathbf{d}\right)$

where $\mathbf{s}$ is the deviatoric stress vector and $\mathbf{d}^{\mathrm{T}}=\{1,1,1,0,0,0\}$. The equivalent plastic strain increment can be derived from Eqs. (26) and (27):

$\Delta \varepsilon_{\mathrm{p}, \mathrm{eq}}^{n}=\Delta \lambda^{n} \sqrt{\frac{1}{3}+\frac{2}{27}\left(\frac{\tan \phi_{\mathrm{d}}}{\alpha_{\mathrm{f}}}\right)^{2}}$

The stress state in each loading step, when plasticity is active, must lie on the Drucker-Prager yield surface, Eq. (23), which relates the equivalent stress $q$ to the hydrostatic pressure $p$ and the material cohesion $c$. Now $q^{n}$ and $p^{n}$ can be expressed through Eqs. (23), (25), (27) in terms of $\boldsymbol{\sigma}^{n-1}$, known from the previous converged loading step, $\Delta \varepsilon_{\mathrm{t}}^{n}$, the input strain increments during the current step, and the unknown plastic multiplier $\Delta \lambda^{n}$. Substitution of $q^{n}\left(\boldsymbol{\sigma}^{n-1}, \Delta \boldsymbol{\varepsilon}_{\mathrm{t}}^{n}, \Delta \lambda^{n}\right)$ and $p^{n}\left(\boldsymbol{\sigma}^{n-1}, \Delta \boldsymbol{\varepsilon}_{\mathrm{t}}^{n}, \Delta \lambda^{n}\right)$ into Eq. (23) leads to a quadratic equation in $\Delta \lambda^{n}$ :

$$
\begin{aligned}
& c_{1}\left(\boldsymbol{\sigma}^{n-1}, \Delta \boldsymbol{\varepsilon}_{\mathrm{t}}^{n}, \varepsilon_{\mathrm{p}, \mathrm{eq}}^{n}\right)\left(\Delta \lambda^{n}\right)^{2} \\
& \quad+c_{2}\left(\boldsymbol{\sigma}^{n-1}, \Delta \boldsymbol{\varepsilon}_{\mathrm{t}}^{n}, \varepsilon_{\mathrm{p}, \mathrm{eq}}^{n}\right) \Delta \lambda+c_{3}\left(\boldsymbol{\sigma}^{n-1}, \Delta \boldsymbol{\varepsilon}_{\mathrm{t}}^{n}, \varepsilon_{\mathrm{p}, \mathrm{eq}}^{n}\right)=0
\end{aligned}
$$




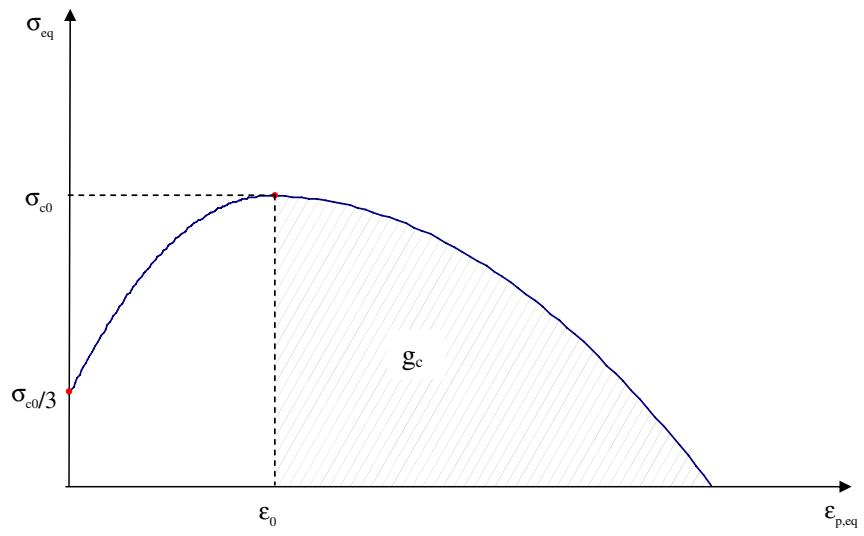

Fig. 4. Adopted inelastic law for the compression regime, with an indication of the compressive fracture energy.

where the coefficients $c_{1}, c_{2}$ and $c_{3}$ depend in general on the equivalent plastic strain $\varepsilon_{\mathrm{p}, \mathrm{eq}}$ through the friction angle $\phi_{\mathrm{f}}$ and the cohesion $c$.

If no strain hardening-softening is present, the coefficients $c_{1-3}\left(\sigma_{n-1}, \Delta \boldsymbol{\varepsilon}_{\mathrm{t}}^{n}\right)$ are known and constant in each loading step and Eq. (29) can be solved directly; otherwise a standard Newton-Raphson method can be used for its solution. In this paper the friction angle is assumed to be independent from the plastic deformation, while a bi-parabolic law in $\varepsilon_{\mathrm{p}, \mathrm{eq}}$ is adopted for the material yield stress. The curve $\sigma_{\mathrm{c}}\left(\varepsilon_{\mathrm{p}, \mathrm{eq}}\right)$, shown in Fig. 4 , is completely defined by the material strength $\sigma_{\mathrm{c} 0}$ (the peak stress), the peak equivalent plastic strain $\varepsilon_{0}$ and the post-peak specific fracture energy $g_{\mathrm{c}}$ :

$$
\begin{aligned}
& \sigma_{\mathrm{c}}=\frac{\sigma_{\mathrm{c} 0}}{3}\left(-2 \frac{\varepsilon_{\mathrm{p}, \mathrm{eq}}^{2}}{\varepsilon_{0}^{2}}+4 \frac{\varepsilon_{\mathrm{p}, \mathrm{eq}}}{\varepsilon_{0}}+1\right) \quad 0 \leqslant \varepsilon_{\mathrm{p}, \mathrm{eq}} \leqslant \varepsilon_{0} \\
& \sigma_{\mathrm{c}}=\sigma_{\mathrm{c} 0}\left\{1-\left[\frac{2 \sigma_{\mathrm{c} 0}}{3 g_{\mathrm{c}}}\left(\varepsilon_{\mathrm{p}, \mathrm{eq}}-\varepsilon_{0}\right)\right]^{2}\right\} \quad \varepsilon_{0} \leqslant \varepsilon_{\mathrm{p}, \mathrm{eq}}
\end{aligned}
$$

The derivative $\frac{\partial c}{\partial \Delta \lambda}=\frac{\partial c}{\partial \varepsilon_{\mathrm{p}, e q}^{n}} \frac{\partial e_{\mathrm{p}, \mathrm{eq}}^{n}}{\partial \Delta \lambda}$, required for the iterative solution of Eq. (29), can be easily obtained by means of Eq. (28).

Once the plastic multiplier $\Delta \lambda^{n}$ is obtained, the increments of plastic strains can be derived, Eq. (27), and the equivalent plastic strain can be updated, Eq. (28), for the next loading step.

\subsection{Considerations on compression-tension model coupling}

With the additional Drucker-Prager model it is possible now to take into account the degradation of the mechanical properties of the cell components due not only to damage in tension, but also to plastic flow of the materials and to hardening-softening of their strengths with increasing deformations. The homogenisation-damage model of the cell internal structure can be coupled with the plasticity model of cell components in the algorithm shown in Fig. 5. In the original basic equilibrium system of the cell,
Eqs. (1)-(12), the strain variables are the elastic strains in the stress-strain relations, Eq. (10), and the total strains in the other equations, derived from geometric considerations on the deformation modes of the model. In [14] elastic and total strains coincide, because plastic deformations were not taken into account. With the introduction of plasticity and of the plastic strains as new additional variables, the total strains are chosen as master variables in all system equations. The system can immediately be applied to the new coupled model, because the stress equilibrium equations are not affected by the introduction of plastic strains, while most of the strain equations are unchanged, being already formulated in terms of total strains. Only Eq. (10), which represent the elastic stress-strain relations, have obviously to be replaced by the usual decomposition of elastic plus plastic strain, resulting in

$\varepsilon_{x x}^{k}=\frac{1}{E_{k}}\left[\sigma_{x x}^{k}-v_{k}\left(\sigma_{y y}^{k}+\sigma_{z z}^{k}\right)\right]+\varepsilon_{p, x x}^{k}$

$\varepsilon_{y y}^{k}=\frac{1}{E_{k}}\left[\sigma_{y y}^{k}-v_{k}\left(\sigma_{x x}^{k}+\sigma_{z z}^{k}\right)\right]+\varepsilon_{p, y y}^{k} \quad k=b, 1,2$

$\varepsilon_{z z}^{k}=\frac{1}{E_{k}}\left[\sigma_{z z}^{k}-v_{k}\left(\sigma_{x x}^{k}+\sigma_{y y}^{k}\right)\right]+\varepsilon_{p, z z}^{k}$

The inner loop in Fig. 5 is an iterative process, in which at each cycle the system of equilibrium equations is solved to obtain the unknown stresses in each masonry component and total strains, making use of the damage coefficients and of the plastic strains of unit and joints from the previous iteration. Both damage and plasticity of each cell component are checked at each loading step. Coupling of damage and plasticity is straightforward, based on the effective stress concept, used e.g. in [18], according to which the plastic deformation is driven by the undamaged stresses. The damage coefficients and the plastic strains can then be updated, respectively, with the new undamaged stresses, by means of the damage model, and with the new total strains, by means of the plasticity model. The process is iterated until convergence of the coefficients and of the strains, within an input tolerance (a value of $10^{-3}$ was used in all calculations). Of course, this coupling leads to some difficulties in case of changes in the loading path and load reversal but additional refinements are outside the scope of the present paper.

The outer loop is the cycle related to the incremental loading steps, in which $\varepsilon_{y y}^{0}$, the normal cell strain perpendicular to the bed joint, is increased, as usual in displacement driven experimental tests. The damaged stresses in the cell components at each loading step can be derived from the values of the converged effective internal stresses. The unknown homogenised cell stress $\sigma_{y y}^{0}$, perpendicular to the bed joint, can finally be obtained as

$\sigma_{y y}^{0}=\frac{l r^{b}}{(l+t)} \sigma_{y y}^{b}+\frac{t r^{2}}{(l+t)} \sigma_{y y}^{2}$ 


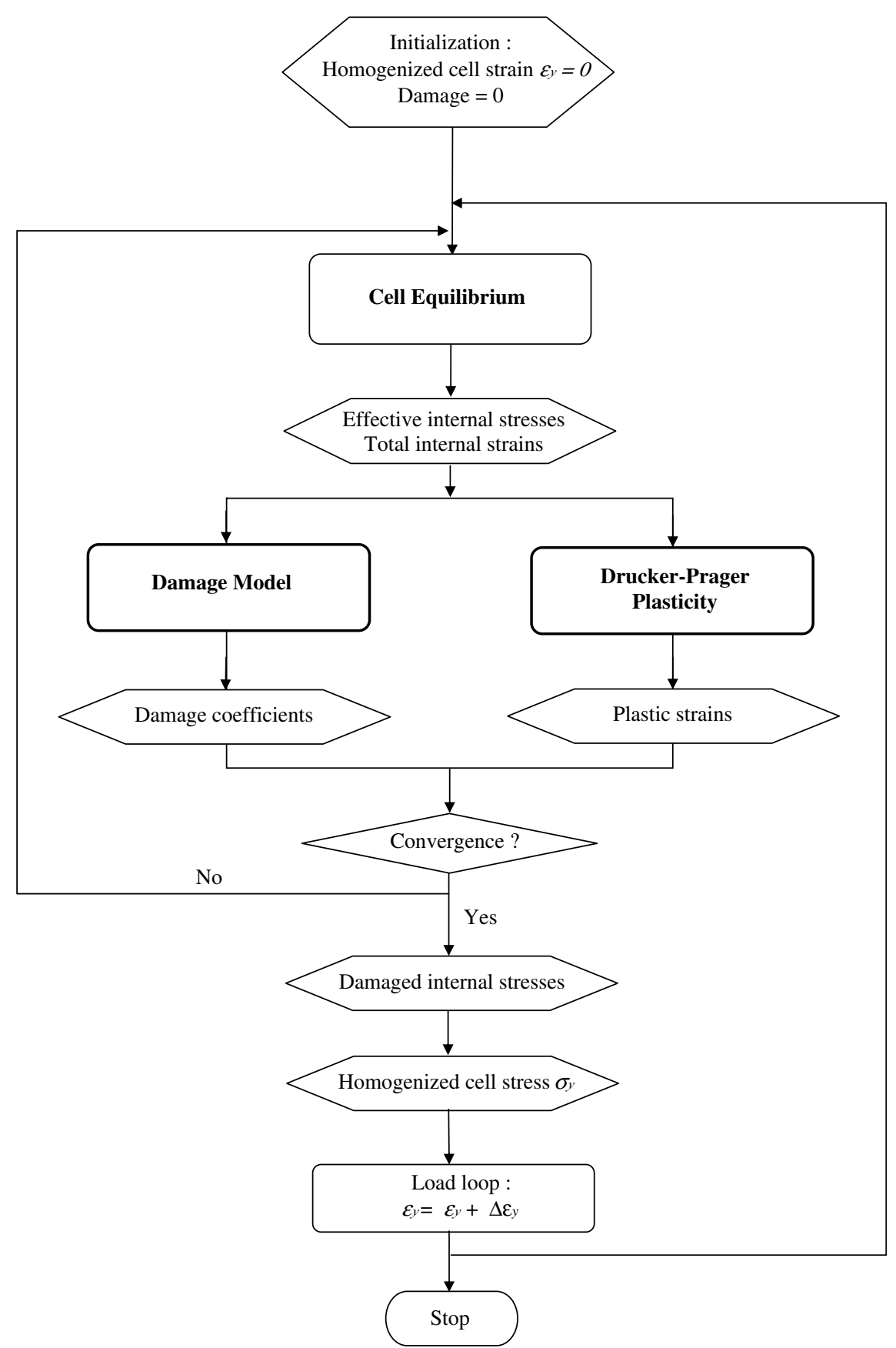

Fig. 5. Iterative procedure for the non-linear homogenisation of a masonry basic cell with tensile damage and compressive plastic behaviour (boxes with bold borders).

\section{Model validation with FEM results}

The homogenisation model, with tension damage and compression plasticity, and the algorithm described in the previous section have been implemented in a computer program for the simulation up to failure of a basic masonry cell under axial compressive loading perpendicular to the bed joint. For this problem numerical results are available from the accurate FEM calculations of Pina-Henriques and Lourenço [10] in the case of a masonry cell with solid soft-mud bricks of dimensions $250 \times 120 \times 55 \mathrm{~mm}^{3}$ and mortar joint thickness of $10 \mathrm{~mm}$. These FEM analyses, aimed at the simulation of the deformation controlled tests of Binda et al. [19], have been carried out with very detailed meshes (see Fig. 6) either in plane stress, plane strain and enhanced plane strain with constant but non-zero normal strains in the out-of-plane direction, being the latter considered the closest possible plane representation of the three-dimensional behaviour.

Considering the symmetry of the cell in Fig. 6, only the upper right quarter (corresponding to the basic cell of the micromechanical model) was modelled in the FEM study 


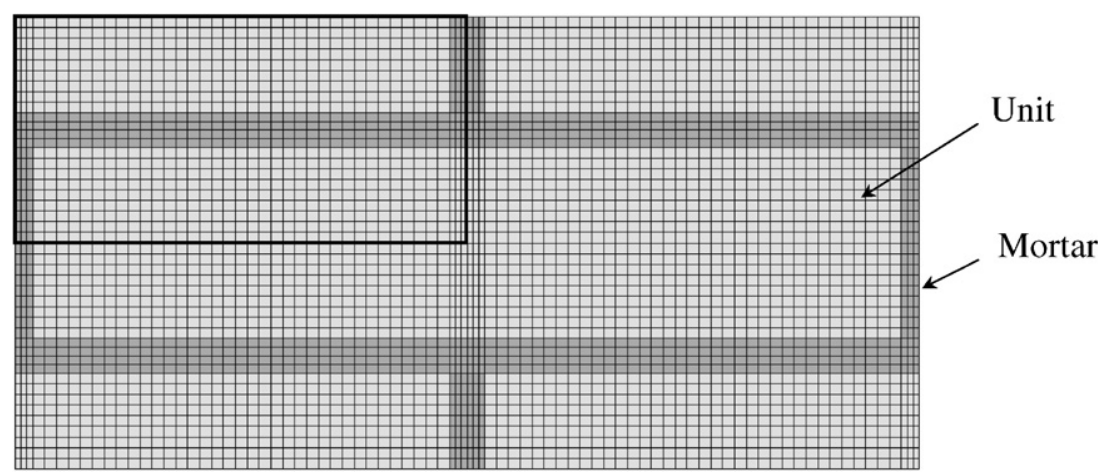

Fig. 6. Model used in the finite element simulations (only the quarter indicated was simulated, assuming symmetry conditions).

and the total number of degrees of freedom was around 7500. Symmetry boundary conditions were assumed for the two sides along the symmetry axes and periodicity conditions for the two sides on the external boundary of the cell. The non-linear behaviour of the cell components has been simulated by means of Drucker-Prager plasticity in compression and Rankine model or cracking in tension. Three different types of mortar were taken into consideration and the material properties used in the analyses are summarized in Table 1. Mortar 1 is a weak mortar, mortars 2 and 3 are stiffer than the brick, and mortar 3 is stronger than the brick.

The material data used by the homogenisation model are exactly the same as in [10]. The homogenisation model requires the exponential coefficient $A$ of the damage in tension, Eq. (15), and the specific compression fracture energy $g_{\mathrm{c}}$, which can be derived from the data in Table 1, respectively, by means of Eq. (16) and of $g_{\mathrm{c}}=\frac{G_{\mathrm{c}}}{l}$ through the characteristic fracture lengths. In tension the characteristic length for the damage model is assumed to be the component dimension perpendicular to the expected crack direction, i.e. $l=10 \mathrm{~mm}$ for the head and bed joint and $l=250 \mathrm{~mm}$ for the brick. In compression, according to a similar "localized" and "mesh independent" approach, the thickness of the material in the direction of the compressive loading is adopted as characteristic length, i.e. $l=10 \mathrm{~mm}$ for the bed joint and $l=55 \mathrm{~mm}$ for the brick.

Table 1

Binda's tests: mechanical properties of the masonry components

\begin{tabular}{|c|c|c|c|c|}
\hline & Unit & $\begin{array}{l}\text { Mortar } \\
\text { type } 1\end{array}$ & $\begin{array}{l}\text { Mortar } \\
\text { type } 2\end{array}$ & $\begin{array}{l}\text { Mortar } \\
\text { type } 3\end{array}$ \\
\hline Young's modulus (MPa) & 4865 & 1178 & 5648 & 17,758 \\
\hline Poisson's coefficient & 0.094 & 0.057 & 0.086 & 0.115 \\
\hline Tensile strength (MPa) & 3.7 & 0.7 & 3.0 & 12.0 \\
\hline $\begin{array}{l}\text { Tensile fracture energy } \\
(\mathrm{N} / \mathrm{mm})\end{array}$ & 1.9 & 0.35 & 0.15 & 0.60 \\
\hline $\begin{array}{l}\text { Compressive strength } \\
(\mathrm{MPa})\end{array}$ & 26.9 & 3.2 & 12.7 & 95.0 \\
\hline $\begin{array}{l}\text { Compr. fracture energy } \\
\qquad(\mathrm{N} / \mathrm{mm})\end{array}$ & 29.8 & 6.43 & 23.8 & 54.8 \\
\hline Friction angle & $10^{\circ}$ & $10^{\circ}$ & $10^{\circ}$ & $10^{\circ}$ \\
\hline Dilatancy angle & $5^{\circ}$ & $5^{\circ}$ & $5^{\circ}$ & $5^{\circ}$ \\
\hline
\end{tabular}

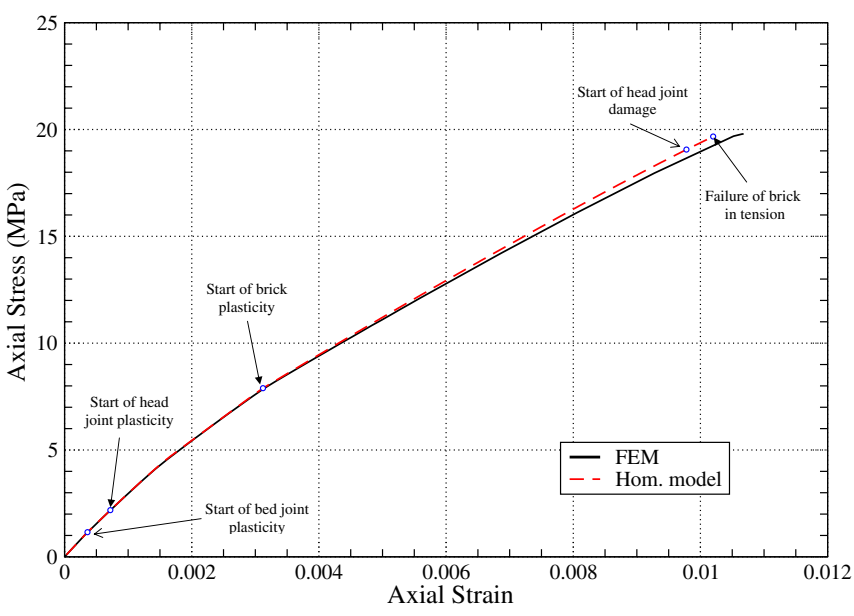

Fig. 7. Axial stress vs. axial strain for prism MU1. Comparison between finite element simulation (Pina-Henriques and Lourenço, 2003) and nonlinear homogenisation model.

The axial stress vs. axial strain curves of both the micromechanical model and the FEM analysis, for masonry prisms with mortar type 1, 2 and 3 (identified, respectively, by MU1, MU2 and MU3), are given in Figs. 7-9. The

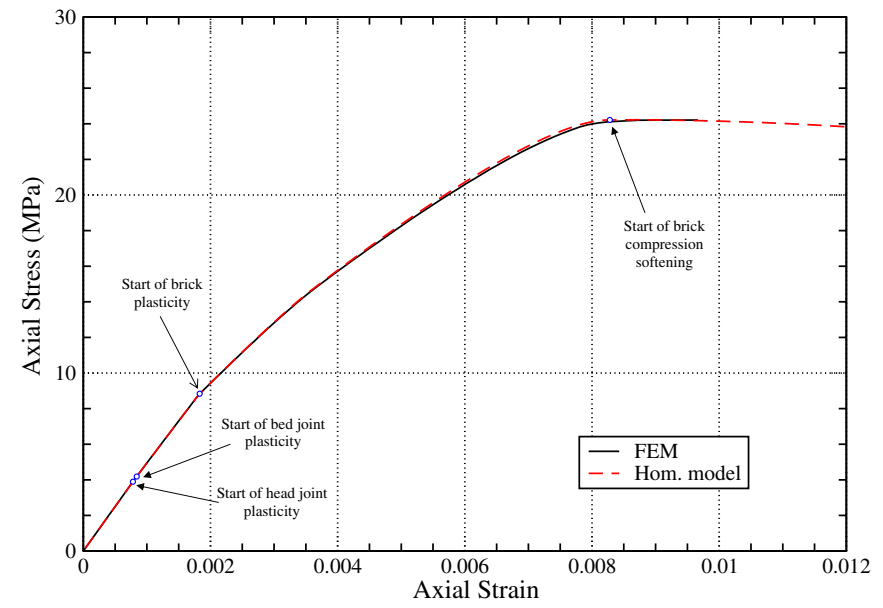

Fig. 8. Axial stress vs. axial strain for prism MU2. Comparison between finite element simulation (Pina-Henriques and Lourenço, 2003) and nonlinear homogenisation model. 


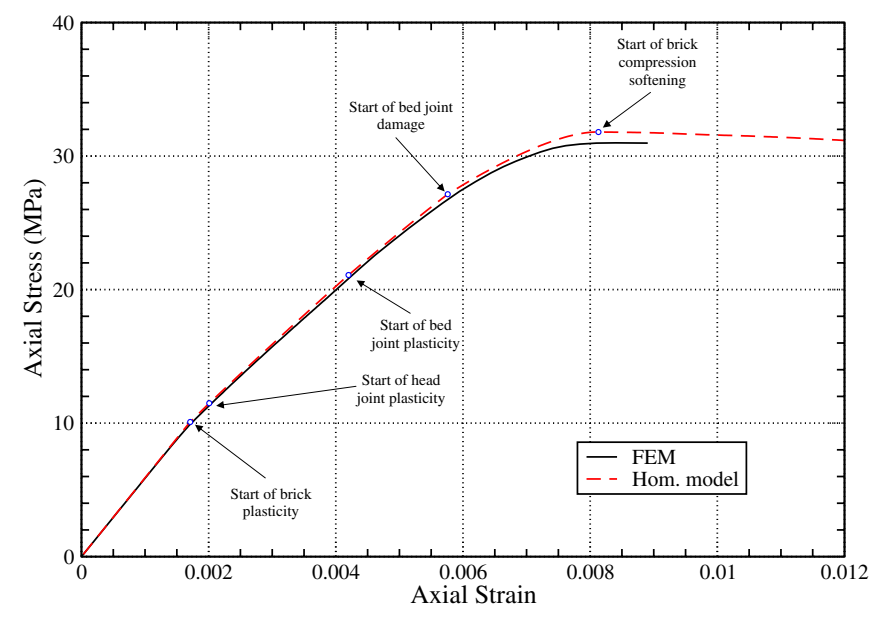

Fig. 9. Axial stress vs. axial strain for prism MU3. Comparison between finite element simulation (Pina-Henriques and Lourenço, 2003) and nonlinear homogenisation model.

curves obtained with the homogenisation model almost coincide with the corresponding FEM results in enhanced plane strain, with marginal computational effort and no convergence difficulties. For cell MU1 (Fig. 7) the plastic flow of the mortar joints starts very early in the loading path, while the brick non-linear behaviour begins a little later. The brick is in a tension-compression-tension state, while the mortar is in a tri-axial compression state for the lateral containment effect of the stiffer brick. The head joint suffers some negligible damage in tension just before the complete failure of the brick in tension, which leads to the catastrophic failure of the entire cell. For the intermediate mortar strength, MU2 (Fig. 8), the brick does not fail in tension because the lower elastic mismatch between the elastic stiffness of the two components is not sufficient for the brick to reach its limit strength, but the cell fails due to the crushing (softening) of the brick itself. In cell MU3 (Fig. 9) the plastic flow starts earlier in the brick than in the bed joint, due to the higher strength of the mortar. The inversion of the elastic mismatch between mortar and brick in this case (the mortar is much stiffer than the brick) yields in this case a tension-tension-compression state of the bed joint. A substantial (57\%) isotropic damage in tension is reached in the bed joint, but the failure of the masonry cell is driven again by the crushing of the brick. The damage of the mortar in the bed is due to the high tension in the $x$ and $z$ direction.

The masonry cell strengths calculated with the homogenisation model for the three different mortar types are summarized in Table 2, where they are compared with the

Table 2

Binda's tests: calculated and measured masonry strength (MPa)

\begin{tabular}{llll}
\hline & FEM & Hom. model & Exp. \\
\hline Prism MU1 & $19.8(80 \%)$ & $19.7(79 \%)$ & 11.0 \\
Prism MU2 & $24.2(67 \%)$ & $24.2(67 \%)$ & 14.5 \\
Prism MU3 & $31.0(74 \%)$ & $31.8(79 \%)$ & 17.8 \\
\hline
\end{tabular}

In brackets the deviation to the experimental value. accurate FEM results of [10]. The agreement is very good in all three cases, with a maximum error below $3 \%$, in the case of the high strength mortar. Here, only the FEM and homogenisation results have been discussed, while the difference between the experimental results and the homogenised results is addressed in the next section.

\subsection{Sensitivity analysis}

Sensitivity analysis is a key issue in masonry due to the usual large scatter of mechanical properties. Here, the effects of a $25 \%$ reduction of unit and mortar strengths (compared to the reference values in Table 1) on the calculated composite strength are shown in Figs. 10 and 11 for prism MU1 and Figs. 12 and 13 for prism MU3. For softer mortar MU1, inducing bi-axial tension in the unit, the key parameters are the tensile and compression strengths of the

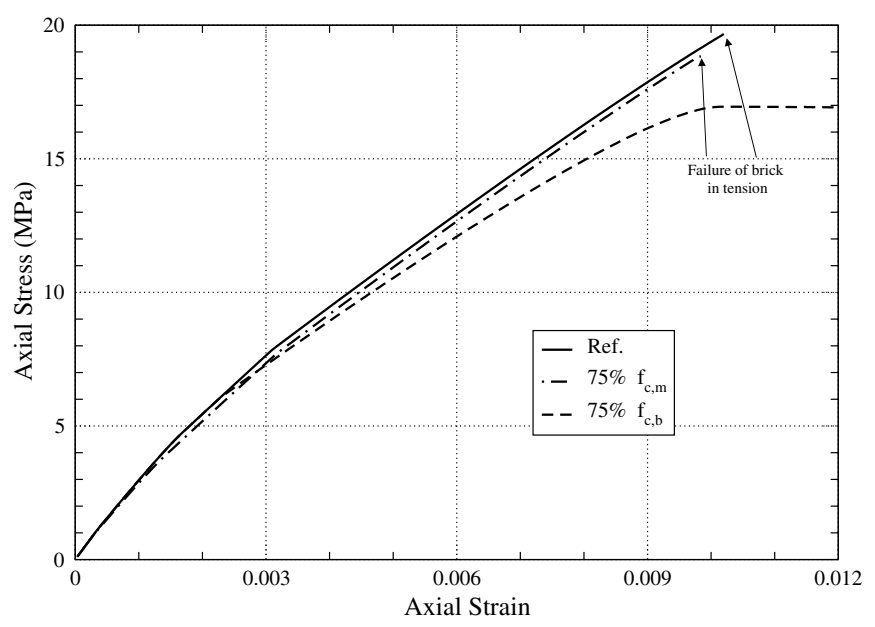

Fig. 10. Axial stress vs. axial strain for prism MU1. Influence of a $25 \%$ reduction in the compressive strength of mortar and brick in the response, using the non-linear homogenisation model.

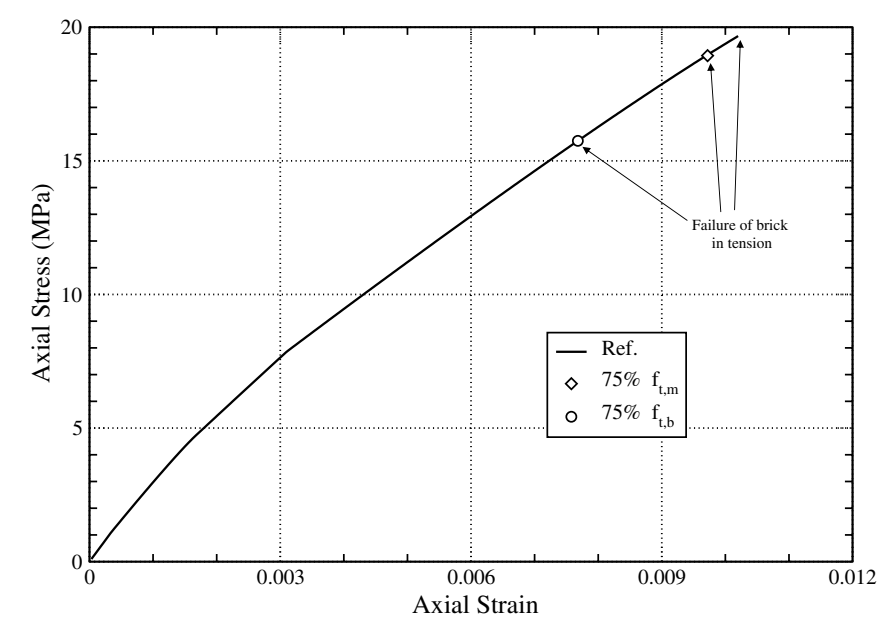

Fig. 11. Axial stress vs. axial strain for prism MU1. Influence of a $25 \%$ reduction in the tensile strength of mortar and brick in the response, using the non-linear homogenisation model. 


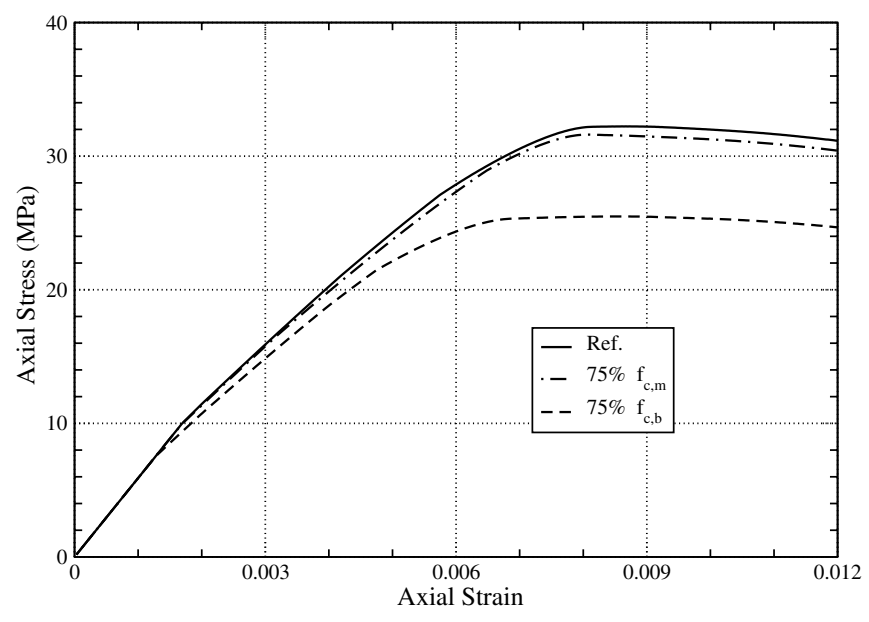

Fig. 12. Axial stress vs. axial strain for prism MU3. Influence of a $25 \%$ reduction in the compressive strength of mortar and brick in the response, using the non-linear homogenisation model.

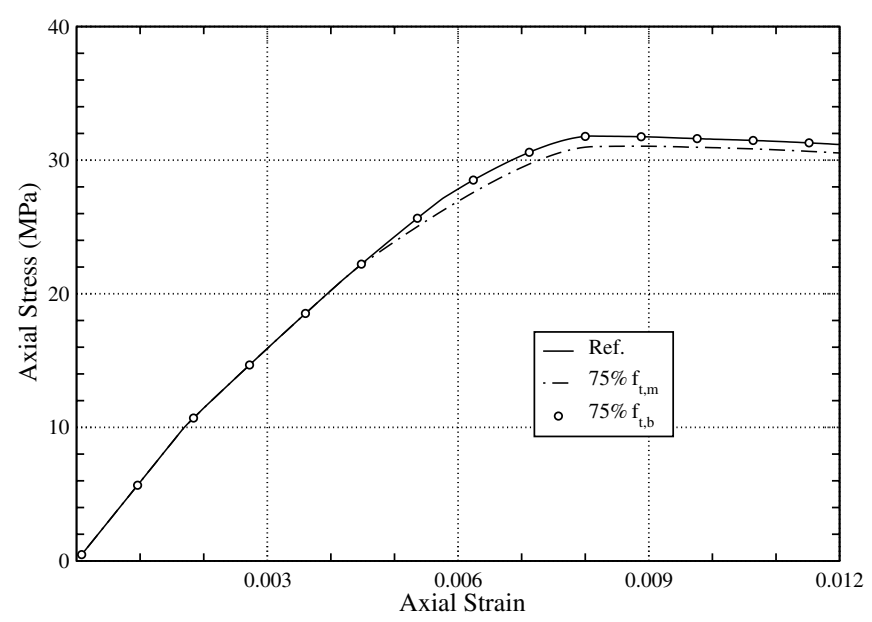

Fig. 13. Axial stress vs. axial strain for prism MU3. Influence of a $25 \%$ reduction in the tensile strength of mortar and brick in the response, using the non-linear homogenisation model.

brick. If the unit compression strength is sufficiently high, the brick fails in tension and the masonry strength is sensitive only to the unit tensile strength $(20 \%$ reduction in Fig. 11). Fig. 10 shows nevertheless that, by decreasing the unit compression strength, the masonry failure mode changes from unit cracking in tension to unit crushing in compression, with a $14 \%$ reduction of the masonry strength. The only key parameter becomes the unit compression strength. In presence of a stiffer and stronger mortar MU3, the unit tensile strength does not play any role in the response because the unit is tri-axially compressed (Fig. 13). The only important parameter in this case is again the unit compression strength with a $21 \%$ reduction shown in Fig. 12. The sensitivity of the response to compression and tensile mortar strengths is much lower.

According to the homogenisation model, the other material properties of the masonry components do not affect the final strength of the composite, but can only change the deformation path of the composite. This work is focused on the masonry strength and a detailed discussion on the non-linear softening of masonry after failure with the present model is left for future research and will not be presented here. Nevertheless, it is stressed that a variation of the Young's modulus of unit and mortar obviously influences the stiffness of the composite, while the value of the compression fracture energies of both components have considerable influence only on the post-peak behaviour of the masonry, when a softening phase is present.

\section{Homogenisation model and experimental results}

For the purpose of validation of the proposed model, and the inherent usage of continuum mechanics for estimation of masonry strength in compression, it is of relevance to consider different testing programs available in the literature. The obvious difficulty is that the material data requested for advanced simulations is usually unavailable. Nevertheless, three independent testing programs are considered next because they have provided a comprehensive description of masonry prisms/wallets and masonry components.

\subsection{Binda's experimental results vs. homogenisation}

The problems used for the validation of the homogenisation model in the previous section are the experimental tests of [19], where masonry prisms, built up with nine courses of bricks in a stretcher bond configuration and with a mortar joint parallel to the face of the prism, are submitted to a deformation controlled compression perpendicular to the bed joint. Three different types of mortar, with material properties given in Table 1, have been used. Prisms MU1, MU2 and MU3 are built with mortars 1, 2 and 3, respectively.

The measured prism strengths are given in Table 2, where they are compared with the numerical results obtained with the homogenisation model and the FEM analysis. The calculated prism strengths overestimate the experimental strengths in all three cases by $70-80 \%$. The results of the micromechanical model are in quite good agreement with the FEM results, so the analytical model proves to be able to catch the main mechanisms triggered by a continuum finite element approach to the simulation of a masonry cell under compression, which is the aim of the proposed homogenisation approach. The FEM stress analysis largely overestimates the strength of the masonry prisms and, as mentioned in the Introduction, that seems a general limitation of standard continuum mechanics in masonry simulation [10]. It can be also mentioned that the Flemish bond in Binda's prisms is different and more complex than the running bond assumed in both the FEM simulation and the homogenisation model. An other issue are also the different curing conditions of the mortar of the specimens and in the prisms, which can lead to very different material properties. 


\subsection{Vermeltfoort's experimental results vs. homogenisation}

Vermeltfoort [3,4] carried out a large number of compression tests on masonry specimens with different types of units and mortars. The brick dimensions are roughly $200 \times 100 \times 50 \mathrm{~mm}^{3}$. Both wallets and prisms were tested. The homogenisation model described in this paper applies to masonry in stretcher bond configuration, therefore the comparison has been carried out with the material strength measured on the wallet, made with two bricks in width and five courses of bricks. The data of the units and the mortars chosen for the numerical simulation are given in Table 3 . Here, VE is a soft mud brick, JG a wire cut brick and $\mathrm{CS}$ a calcium silicate brick. The mechanical data have been obtained by testing of unit and mortar prisms independently [4] with the exception of the tensile fracture energy of units [20]. The tensile behaviour of mortar has been considered linear elastic because the influence in the results is minor, as shown in Section 3.1.

The calculated masonry strengths are given in Table 4, together with Vermeltfoort's experimental results, for the six masonry wallets taken into account. There is a large variation of the error (from $-17 \%$ to $+93 \%$ ), with the numerical values always overestimating the experimental ones, except in one case. The calculated strength is almost constant for the samples with the same mortar but different unit, while the measured data varies significantly. The reason for this behaviour of the homogenisation model is that, as shown in Section 3.1, in this case the main brick parameter, driving the compression response of the specimen, is the brick tensile strength, which is almost identical in the three bricks. The correctness of the experimental results are not under discussion here but it is noted that a unusually large anisotropy was found for the strength of brick VE, with a tensile strength in the vertical direction of only $1.5 \mathrm{~N} / \mathrm{mm}^{2}$.

\subsection{McNary's experimental results vs. homogenisation}

The homogenisation model has been compared also with the numerical and experimental results of McNary and Abrams [5]. McNary's computational model is based
Table 4

Vermeltfoort's tests: calculated and measured masonry strength (MPa)

\begin{tabular}{lllllr}
\hline & \multicolumn{2}{l}{ Mortar 1:1/2:41/2 } & & \multicolumn{2}{l}{ Mortar 1:2:9 } \\
\cline { 2 - 3 } \cline { 5 - 6 } & Hom. model & Exp. & & Hom. model & Exp. \\
\hline Unit JG & $20.9(15 \%)$ & 18.2 & & $12.4(38 \%)$ & 9.0 \\
Unit CS & $21.0(8 \%)$ & 19.4 & & $12.4(-17 \%)$ & 14.9 \\
Unit VE & $21.9(97 \%)$ & 11.1 & & $12.6(68 \%)$ & 7.5 \\
\hline
\end{tabular}

In brackets the deviation to the experimental value.

on the theory proposed by [21], a simple elastic mechanical model for stack-bond masonry, where mortar Young's modulus and Poisson's coefficient are expressed as functions of the vertical and lateral stresses. These functions account for the non-linear behaviour of mortar and have to be determined by tri-axial compression tests. Four mortar types and two bricks types (an "under-burned paver" and a "colonial satin cored") have been used for the tests and combined in eight different masonry prisms of one brick width. The material properties found by McNary's tests and other sources for mortars and units are given in Table 5. The mechanical data have been obtained by testing of unit and mortar prisms independently [22] with the exception of the tensile and compressive fracture energy of units, estimated from [23]. The tensile behaviour of mortar has been considered again linear elastic.

Calculated and measured prism strengths are shown in Table 6. The homogenisation model results show a significant improvement compared to the McNary's analysis (the average error decreases from $32 \%$ to $10 \%$ ) and are in good agreement with the experimental values.

\subsection{Experimental results vs. simplified formulas}

Masonry strength can be estimated by means of formulas based on simplified models or code specifications. In Table 7 the experimental and homogenisation model results are compared with the values obtained with the equations proposed by [24-26] and the specifications of CEN [11] and ACI [12]. In the ACI equation the mean strength $f_{\mathrm{c}}$ has been calculated from the specified design strength $f_{\mathrm{m}}$ assuming $f_{\mathrm{c}}=f_{\mathrm{m}}+1.34 \sigma$, with the standard deviation $\sigma=10 \% f_{\mathrm{c}}$. Similarly in the CEN equation the

Table 3

Vermeltfoort's tests: mechanical properties of the masonry components

\begin{tabular}{|c|c|c|c|c|c|}
\hline & Unit JG & Unit CS & Unit VE & Mortar 1:1/2:41/2 & Mortar 1:2:9 \\
\hline Dimensions (mm) & $204 \times 98 \times 50$ & $212 \times 100 \times 53$ & $208 \times 98 \times 50$ & 12.5 & 12.5 \\
\hline Young's modulus (MPa) & 16,700 & 13,400 & 6000 & 1000 & 500 \\
\hline Poisson's coefficient & 0.28 & 0.25 & 0.14 & 0.15 & 0.15 \\
\hline Tensile fracture energy $(\mathrm{N} / \mathrm{mm})$ & 0.068 & 0.068 & 0.072 & $\infty$ & $\infty$ \\
\hline Tensile characteristic length $(\mathrm{mm})$ & 204 & 212 & 208 & - & - \\
\hline Compressive strength (MPa) & 66 & 40 & 32 & 12 & 4 \\
\hline Friction angle & $10^{\circ}$ & $10^{\circ}$ & $10^{\circ}$ & $10^{\circ}$ & $10^{\circ}$ \\
\hline Dilatancy angle & $5^{\circ}$ & $5^{\circ}$ & $5^{\circ}$ & $5^{\circ}$ & $5^{\circ}$ \\
\hline
\end{tabular}


Table 5

McNary's tests: mechanical properties of the masonry components

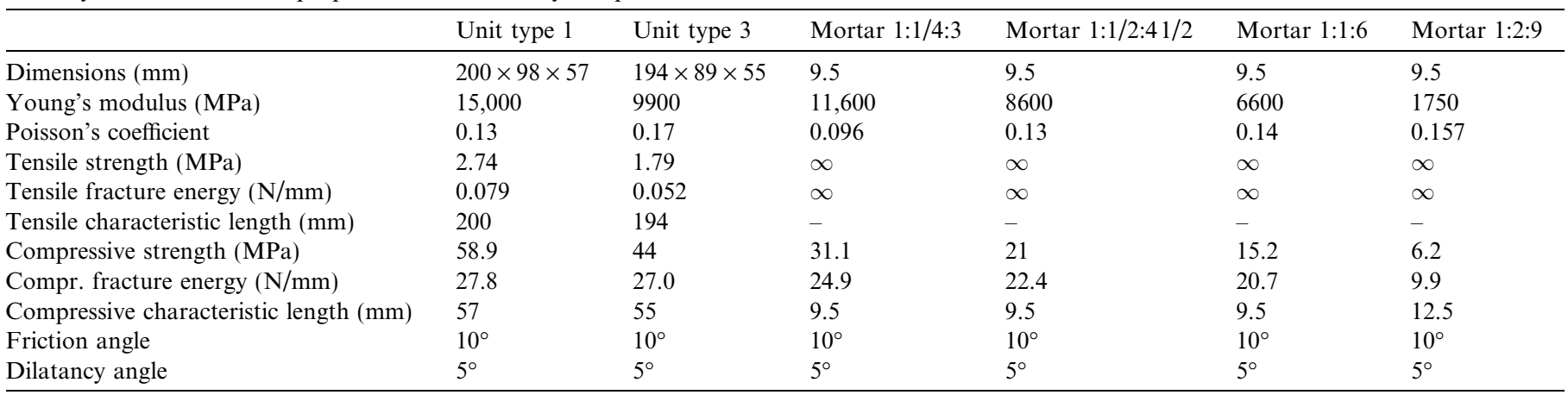

Table 6

McNary's tests: calculated and measured prism strength (MPa)

\begin{tabular}{|c|c|c|c|c|c|c|}
\hline \multirow[t]{2}{*}{ Mortar } & \multicolumn{3}{|l|}{ Unit type 1} & \multicolumn{3}{|l|}{ Unit type 3} \\
\hline & Hom. model & Exp. & McNary & Hom. model & Exp. & McNary \\
\hline $1: 1 / 4: 3$ & $46.9(-3 \%)$ & 48.2 & $34.2(-29 \%)$ & $40.2(7 \%)$ & 37.7 & $23.8(-37 \%)$ \\
\hline $1: 1 / 4: 41 / 2$ & $37.9(-7 \%)$ & 40.9 & $28.8(-30 \%)$ & $31.8(-8 \%)$ & 34.7 & $21.9(-37 \%)$ \\
\hline $1: 1: 6$ & $31.0(-5 \%)$ & 32.5 & $25.8(-21 \%)$ & $25.3(-6 \%)$ & 27.0 & $17.7(-35 \%)$ \\
\hline $1: 2: 9$ & $21.8(-27 \%)$ & 29.9 & $18.1(-40 \%)$ & $16.5(-16 \%)$ & 19.7 & $13.7(-31 \%)$ \\
\hline
\end{tabular}

In brackets the deviation to the experimental value.

Table 7

Comparison between all measured masonry strengths and prediction using simplified formulations (Mpa)

\begin{tabular}{|c|c|c|c|c|c|c|c|c|c|}
\hline \multicolumn{3}{|l|}{ Test } & \multirow{2}{*}{$\begin{array}{l}\text { Exp. } \\
11.0\end{array}$} & \multirow{2}{*}{$\begin{array}{c}\text { Francis } \\
\mathbf{2 5 . 7}\end{array}$} & \multirow{2}{*}{$\frac{\text { Khoo and Hendry }}{\mathbf{1 5 . 2}}$} & \multirow{2}{*}{$\begin{array}{r}\text { Ohler } \\
14.8\end{array}$} & \multirow{2}{*}{$\begin{array}{r}\text { CEN } \\
7.5\end{array}$} & \multirow{2}{*}{$\frac{\mathrm{ACI}}{9.4}$} & \multirow{2}{*}{$\frac{\text { Hom Model }}{19.7}$} \\
\hline Binda & MU1 & & & & & & & & \\
\hline & MU2 & & 14.5 & 28.1 & 20.2 & 19.0 & 11.3 & 11.0 & 24.2 \\
\hline & MU3 & & 17.8 & - & - & - & 13.0 & 11.0 & 31.8 \\
\hline \multirow[t]{4}{*}{ Vermeltfoort } & JG & $1: 112: 4112$ & 18.2 & 31.5 & 25.7 & 22.6 & 26.0 & 22.2 & 20.9 \\
\hline & & $1: 2: 9$ & 9.0 & 30.5 & 18.1 & 16.4 & 18.7 & 18.4 & 12.4 \\
\hline & $\mathrm{CS}$ & $1: 1 / 2: 4112$ & 19.4 & 20.1 & 18.6 & 17.3 & 15.0 & 11.8 & 21.0 \\
\hline & & $1: 2: 9$ & 14.9 & 19.6 & 13.5 & 12.2 & 10.8 & 10.1 & 12.4 \\
\hline \multirow[t]{5}{*}{ McNary } & Unit 1 & 1:114:3 & 48.2 & 60.0 & 40.3 & 41.1 & 28.0 & 20.2 & 46.9 \\
\hline & & $1: 1 / 2: 4112$ & 40.9 & 50.3 & 35.0 & 35.4 & 28.0 & 20.2 & 37.9 \\
\hline & & 1:1:6 & 32.5 & 43.8 & 30.9 & 28.6 & 25.8 & 16.8 & 31.0 \\
\hline & & $1: 2: 9$ & 29.9 & 36.7 & 24.1 & 22.0 & 19.7 & 16.8 & 21.8 \\
\hline & Unit 3 & $1: 114: 3$ & 37.7 & - & - & - & 22.8 & 15.9 & 40.2 \\
\hline
\end{tabular}

mean masonry strength has been obtained from the characteristic strength $f_{\mathrm{c}, k}$ with $f_{\mathrm{c}}=f_{\mathrm{c}, k}+1.64 \sigma$ and $\sigma=10 \% f_{\mathrm{c}}$. In Table 7 the numbers in bold indicate predicted strengths above the experimentally measured values. Francis's equation provides too high values and should not be used. ACI and $\mathrm{CEN}$ provide in general rather conservative values (up to $40 \%$ of the experimental value). The homogenisation model gives its best performance in the McNary's test and its worst in the Binda's tests. On average the error of the homogenisation procedure is similar to Ohler's and
Hendry's equations, being between the lowest of all considered approaches. It can be also observed that in Vermeltfoort's cases with clay bricks even the ACI and CEN specifications fail to be a conservative prediction of the masonry strength.

\section{Conclusions}

The present paper addresses two different issues, namely a novel non-linear homogenisation approach for masonry 
including tensile damage and compressive plasticity, and a comparison between the homogenised approach and experimental results of masonry under compression.

The main goal of the paper is to show that the proposed homogenised model can reproduce almost exactly the results of a non-linear finite element calculation, at a marginal fraction of the computational effort. In addition, it is shown that the strength of mortar has limited influence in the response of the masonry composite, but the results are more sensitive to the unit compression strength and unit tensile strength. This last parameter is only relevant if the unit is subjected to bi-axial tension, which is the usual case of masonry built using weak mortars.

A comparison, focused on the ultimate masonry strength (in most cases the only experimental result available), between the model, three different testing programs and several simplified formulas, indicate that all the different approaches (including the homogenised model) are incapable of reproducing the experimental results. It is well known that the mechanical properties of mortar inside a composite can be quite different from the properties of specimens cast separately of the same mortar, due to different curing conditions. Another issue is that the volumetric behaviour of tri-axially compressed solids requires a cap model for an accurate description of volume change. These effects can justify some of the differences found between homogenised and experimental values but the key issue seems to be a general limitation of continuum mechanics. Alternative discontinuum modelling approaches that consider the micro-structure of quasi-brittle materials seem therefore needed to study the uniaxial compressive behaviour of masonry.

\section{References}

[1] CEN. Methods of test for masonry. Determination of compressive strength. EN 1052-1:1999, 1999.

[2] Mann W, Betzler M. Compressive strength of masonry parallel to the bed joints. In: Proc 10th Int Brick and Block Masonry Conf, University of Calgary, 1994. p. 1305-13.

[3] Vermeltfoort AT. Compression properties of masonry and its components. In: Proc 10th Int Brick and Block Masonry Conf, University of Calgary, 1994. p. 1433-42.

[4] Vermeltfoort AT. Brick-mortar interaction in masonry under pressure. $\mathrm{PhD}$ thesis, Eindhoven University of Technology, The Netherlands, 2005.

[5] Hendry AW. Structural masonry. 2nd ed. MacMillan Publisher; 1998.
[6] Hilsdorf HK. Investigation into the failure mechanism of brick masonry loaded in axial compression. Designing, engineering and constructing with masonry products. Gulf Publishing Company; 1969. p. $34-41$.

[7] McNary WS, Abrams DP. Mechanics of masonry in compression. J Struct Eng ASCE 1985;111(4):857-70.

[8] Brencich A, Corradi C, Gambarotta L, Mantegazza G, Sterpi E. Compressive strength of solid clay brick masonry under eccentric loading. Proc Br Masonry Soc 2002;9:37-46.

[9] Shrive NG, Jessop EL. An examination of the failure mechanism of masonry piers, prisms and walls subjected to compression. Proc $\mathrm{Br}$ Ceram Soc 1982;30:110-7.

[10] Pina-Henriques J, Lourenço PB. Testing and modelling of masonry creep and damage in uniaxial compression. Proc 8th STREMAH. WIT Press; 2003. p. 151-60.

[11] CEN. Eurocode 6: design of masonry structures. prEN 1996-11:2002, Brussels, Belgium, 2003.

[12] ACI. Commentary on specification for masonry structures. ACI 530.1-02, Manual of concrete practice, Detroit, USA, 2004.

[13] Zucchini A, Lourenço PB. A micro-mechanical model for the homogenisation of masonry. Int J Solids Struct 2002;39:3233-55.

[14] Zucchini A, Lourenço PB. A coupled homogenisation-damage model for masonry cracking. Comput Struct 2004;82:917-29.

[15] Bazant ZP. Size effect on structural strength: a review. Arch Appl Mech 1999;69:703-25.

[16] Zienkiewicz OC, Taylor RL. The finite element method: Volume $2-$ Solid mechanics. 5th ed. Butterworth-Heinemann; 2000.

[17] Lourenço PB. Computational strategies for masonry structures. PhD thesis, Delft University of Technology, 1996. Available from: www.civil.uminho.pt/masonry.

[18] Lemaitre J. How to use damage mechanics. Nucl Eng Des 1984;80:233-45.

[19] Binda L, Fontana A, Frigerio G. Mechanical behaviour of brick masonries derived from unit and mortar characteristics. In: Proc 8th Int Brick and Block Masonry Conf, Dublin, 1988.

[20] Van der Pluijm. Non-linear behaviour of masonry under tension. Heron 1997;42(1):25-54.

[21] Atkinson RH, Noland JL. A proposed failure theory for brick masonry in compression. In: Proc 3rd Canadian masonry symposium, Edmonton, Canada, 1983. p. 5.1-5.17.

[22] McNary WS. Basic properties of clay-unit masonry in compression. MSc thesis, University of Colorado, USA, 1981.

[23] Lourenço PB. A user/programmer guide for the micro-modelling of masonry structures. Report 03.21.1.31.35, Delft University of Technology, 1996. Available from: www.civil.uminho.pt/masonry.

[24] Francis A, Horman C, Jerrems L. The effect of joint thickness and other factors on the compressive strength of brickwork. In: Proc 2nd Int brick and block masonry Conf, Stoke-on-Trent, UK, 1971. p. 31-7.

[25] Khoo C, Hendry A. A failure criterion for brickwork in axial compression. In: Proc 3rd Int brick and block masonry Conf, Essen, Germany, 1973, p. 139-45.

[26] Ohler A. Zur berechnung der druckfestigeit von mauerwerk unter berucksichtigung der mehrachsigen spannungszustande in stein und mortel. Bautechnik 1986:5. 